\title{
A formação de professores reflexivos: a docência como objeto de investigação
}

The reflective teacher education: teaching as an object of research

\author{
Altair Alberto Fávero* \\ Universidade de Passo Fundo \\ Carina Tonieto** \\ Universidade de Passo Fundo \\ Marisa Fátima Roman*** \\ Universidad Autónoma del Estado de México
}

Resumo A formação continuada de professores tornou-se assunto obrigatório em nosso tempo. Há um consenso entre os professores e dirigentes escolares que é necessário "educar os educadores", pois os saberes racionais que foram aprendidos nos processos formativos não são suficientes para enfrentar a complexidade e a diversidade dos problemas que o trabalho docente exige. É necessário e urgente, em qualquer área de atuação, refletir sobre novas formas de exercer os saberes necessários para a prática profissional. No que se refere ao trabalho docente, a reflexão na e sobre a prática possibilita que o educador reveja sua própria atuação. O presente texto tem como principal foco analisar a formação continuada de professores a partir do paradigma do professor reflexivo.

Palavras-chave: Reflexivo, Processo formativo, Políticas educacionais.

Abstract The continuing education of teachers has become a compulsory subject in our time. There is a consensus among teachers and school leaders regarding the need to "educate the educators", because the rational knowledge learned in the process of formation of teachers is not sufficient to face the complexity and the diversity of the problems that the teachers' work demands. It is necessary and urgent, in any area from education, to reflect about the new forms of exercising the skills needed for the professional practice. In regards to teaching, reflecting in and about the practice enables the educator to reconsider their own performance. The focus of this essay is to analyze the continuing education of teachers from the paradigm of the reflective teacher.

KEYWORDS: Reflective teacher, Formative process, Educational policies. 


\section{Considerações iniciais}

Vivemos tempos difíceis na educação decorrentes de um conjunto de movimentos, de mudanças, de dispersão, de sintomas de épocas. Fala-se em crise, caos, apatia, desinteresse, desconfiança, ceticismo, mal-estar, violência, morte das utopias. O contexto escolar se mostra paradoxal: se de um lado há um entusiasmado anúncio de que os índices de acesso à escola atingiram seu ápice, que há "polpudas" verbas destinadas à pasta ministerial da educação, que está havendo um crescimento progressivo do ensino superior, que estão sendo ampliados os números absolutos da pós-graduação, que as iniciativas de educação a distância e a efetivação de políticas afirmativas estão oportunizando o acesso à escola formal daqueles que não puderam frequentá-la no período normal; por outro se constata um conjunto de situações preocupantes marcadas por diversas contradições que obstaculizam o ato da educação ocupar o lugar que lhe compete na realização de uma sociedade justa e democrática.

A partir desse quadro paradoxal poderíamos abrir um leque de questionamentos: para onde vai a educação escolar? Quais são as raízes de todos estes problemas? Que desafios precisam ser enfrentados urgentemente para que não percamos a oportunidade de tornar a educação o motor da história que trará suporte para construir uma sociedade democrática e menos injusta? Que papel os docentes estão ocupando neste processo de mudança? Que lacunas possuem no seu processo formativo? De que maneira a formação continuada pode contribuir para enfrentar de forma mais otimista este quadro desolador em que se encontra a escola? Em que perspectiva pode ser pensada a educação continuada? Certamente não será possível enfrentar cada uma destas questões e muitas outras que poderiam ser acrescentadas no curto espaço deste texto. No entanto, nossa hipótese de trabalho é que boa parte deste quadro problemático poderá ser enfrentado com mais serenidade se cuidarmos da formação docente. Acreditamos que a formação continuada requer uma atenção especial, pois é a partir dela que poderemos enfrentar de forma pontual certas defasagens que encontramos nas práticas docentes. Assim, o objetivo do presente texto é construir algumas reflexões sobre a formação continuada a partir da perspectiva do professor reflexivo.

\section{A racionalidade técnico-instrumental na formação docente}

Há uma certa unanimidade entre os educadores, gestores educacionais e sociedade em geral que os impactos das transformações provocadas pela sociedade da informação exige da escola e de seus protagonistas uma reavaliação do seu papel no atual cenário. Não resta dúvida que a escola, considerada a instituição soberana na era industrial no que se refere ao processo da transmissão e socialização do saber, encontra-se hoje diante do difícil desafio de reencontrar seu lugar no cenário da sociedade da informação. No entanto, conforme nos adverte Libâneo, "por mais que a escola básica seja afetada em suas funções, na sua estrutura organizacional, nos seus conteúdos e métodos, ela se mantém como instituição necessária à democratização da sociedade" (2004, p. 7). Em função 
disso, é necessário (re)pensar e (re)definir as características da nova identidade da escola e por consequência o perfil dos seus principais protagonistas, os professores. No dizer de Libâneo, "não há reforma educacional, não há proposta pedagógica sem professores, já que são os profissionais mais diretamente envolvidos com os processos e resultados da aprendizagem escolar" (2004, p. 7). Nesse aspecto, a formação de professores certamente ocupa um lugar central para que o discurso em favor de uma profunda reforma educacional não se restrinja aos limites do discurso. Mas no que consiste a formação de professores? Por que é necessário planejar e articular uma formação continuada? Que referências poderiam dar-lhe suporte?

Em seu texto "o pensamento prático do professor: a formação do professor como profissional reflexivo", Angel Pérez Gómez, professor da Universidade de Málaga (Espanha), descreve a preocupação da sociedade ocidental quanto aos resultados insatisfatórios dos longos e custosos processos de escolarização. Para Pérez Gómez, "nas sociedades industrializadas, a escola conseguiu chegar aos lugares mais inacessíveis e às camadas sociais mais desfavorecidas". Não obstante, adverte ele, "nem a preparação científico-técnica, nem a formação cultural e humana, nem sequer a desejada formação compensatória alcançaram o grau de satisfação prometido" (1995, p. 95).

Pérez Gómez defende a tese de que não é possível abordar esta problemática sem enfrentar a "questão da formação do professor" e como tal questão se articula com os conceitos de escola, ensino e currículo. Dessa articulação "desenvolvem-se imagens e metáforas que pretendem definir a função do docente como profissional na escola e na aula" (PÉREZ GÓMEZ, 1995, p. 95-96). Pérez Gómez detém-se em duas metáforas de professor que expressam duas concepções distintas de intervenção educativa na atividade do docente como profissional de ensino: a) o professor como técnico-especialista; b) o professor como profissional reflexivo. Qual o perfil de cada um desses personagens? Quais suas principais características? No que sua identidade pode nos auxiliar na formatação de um projeto de formação continuada?

Para Pérez Gómez, o professor como técnico-especialista deita suas raízes "na concepção epistemológica da prática herdada do positivismo, que prevaleceu ao longo de todo o século XX, servindo de referência para a educação e socialização dos profissionais em geral e dos docentes em particular" (1995, p. 96). Trata-se da aplicação da racionalidade técnica, em que a atividade profissional se reduz à aplicação instrumental de um conjunto de saberes na resolução de problemas. Há uma hierarquia de saberes que poderiam ser dispostos da seguinte maneira: a) saberes provenientes da ciência básica responsável pela produção dos conhecimentos teóricos que dão suporte ou fundamento à ciência aplicada; b) saberes no âmbito da ciência aplicada que possibilitam o diagnóstico e a solução de problemas cotidianos; e por fim c) saberes competentes e atitudinais que possibilitam a intervenção e aproximação nas situações práticas em que são requeridos. 
$\mathrm{Na}$ interpretação de Pérez Gómez, essa hierarquização de saberes tornou-se responsável pela divisão social do trabalho (aqueles que pensam versus aqueles que escutam), criando com isso "uma relação de subordinação dos níveis mais aplicados e próximos da prática aos níveis mais abstratos de produção do conhecimento, ao mesmo tempo que as condições para o isolamento dos profissionais e para a sua confrontação corporativa" (1995, p. 97).

$\mathrm{Na}$ racionalidade técnica há uma nítida separação entre a investigação e a prática: os investigadores da ciência básica proporcionam os saberes necessários que serão mecanicamente aplicados pelos executores desses saberes. Com Habermas (1982), é possível dizer que a racionalidade técnica reduz a atividade prática à análise dos meios apropriados para atingir determinados fins. Com isso há um esquecimento do caráter moral e político que perpassa a definição dos fins em toda e qualquer ação profissional que tem a intenção de resolver problemas humanos. Restringir a racionalidade prática nos moldes da racionalidade instrumental significa operar com a ideia de que a ação de um determinado profissional se limita "a aceitar a definição externa das metas de sua intervenção" (PÉREZ GÓMEZ, 1995 p. 97). Em termos educacionais, "a concepção de ensino como intervenção tecnológica", "a invenção baseada no paradigma processoproduto", "a concepção do professor como técnico" e mesmo a ideia de "formação de professores por competências" são, para Pérez Gómez, "indicadores eloquentes da amplitude temporal e espacial do modelo de racionalidade técnica" (1995, p. 98).

A abordagem comportamentalista do ensino, que se desenvolveu a partir da década de 1950 e que ganhou um incentivo especial no Brasil a partir da Lei de Diretrizes e Bases da Educação (LDB) 5692/71, é um exemplo para diagnosticar a presença da racionalidade técnico-instrumental no processo educacional. Ancorada na psicologia do comportamento, esta "tecnologia educativa" reduz a imagem do professor a de um técnico especializado "que aplica as regras que derivam do conhecimento científico, sistemático e normatizado" (PÉREZ GÓMEZ, 1995, p. 98). A abordagem comportamentalista de ensino parte dos pressupostos de que o "conhecimento é uma descoberta", de que o "comportamento humano é modelado e reforçado", de que "a educação deve limitar-se aos aspectos mensuráveis e observáveis", de que "o conteúdo transmitido visa objetivos e habilidades que levem à competência", de que "o aluno é considerado como um recipiente de informações", e de que "o ensino é composto por padrões de comportamento que podem ser mudados através de treinamento". Nesse tipo de abordagem "supõe-se e objetiva-se que o professor possa aprender e analisar os elementos específicos de seu comportamento, seus padrões de interação, para, dessa forma, ganhar controle sobre eles e modificá-los em determinadas direções quando necessário, ou mesmo desenvolver outros padrões" (MIZUKAMI, 1986, p. 20-21). Não podemos esquecer que em boa parte dos últimos 40 anos a educação brasileira foi profundamente marcada por essa abordagem comportamentalista, não só na formação de professores nos cursos de licenciaturas no Ensino Superior e, consequentemente, nas práticas educacionais da Educação Básica. 
Para os comportamentalistas, o ser humano é produto das influências ou forças existentes do meio em que vive. Portanto, não é livre. Burrhus Frederic Skinner, considerado um dos mais influentes teóricos do comportamentalismo educacional do Brasil, estava tão convicto que era possível transferir o controle da situação ambiental para o próprio sujeito que assim se pronunciava:

Se vamos usar os métodos da ciência no campo dos assuntos humanos, devemos pressupor que o comportamento é ordenado e determinado. Devemos esperar descobrir que o que o homem faz é o resultado de condições que podem ser especificadas e que, uma vez determinadas, poderemos antecipar e até certo ponto determinar as ações. (apud MIZUKAMI, 1986, p. 21)

A realidade, o ambiente educativo e a própria noção de ser humano são, nessa abordagem técnico-instrumental-comportamentalista, fenômenos objetivos que podem ser manipulados e modificados através de intervenções e controle do ambiente, pois o meio pode ser manipulado. Esta concepção linear e simplista dos processos de ensino tem impregnado a formação de professores em boa parte dos processos formativos das três últimas décadas do século XX. Tornar-se professor nessa concepção significa adquirir o conhecimento de princípios, leis e teorias que explicam os processos de ensino-aprendizagem e aplicar normas e regras que possibilitam uma intervenção eficaz no processo educativo. $\mathrm{Na}$ avaliação de Pérez Gómez (1995, p. 98), "com uma ou outra adaptação, a maioria dos programas de formação de professores integram-se dentro deste esquema, na medida em que se baseiam no modelo de racionalidade técnica ou instrumental". Quais os limites e lacunas desse modelo de formação docente? Por que durante tanto tempo a racionalidade técnica prevaleceu como protótipo de modelo formativo dos professores?

Segundo Pérez Gómes (1995, p. 99), "não é difícil reconhecer o progresso que a racionalidade técnica representa relativamente ao empirismo voluntarista e ao obscurantismo teórico das teses vulgarmente denominadas "tradicionalistas". Por muito tempo, a formação de professores foi concebida como sendo um processo de socialização e indução profissional na prática cotidiana. Ser professor nesse contexto "tradicionalista" era imitar um protótipo de professor bem-sucedido. Por sua vez, a perspectiva técnico-racionalista passa a propor e defender "a aplicação do conhecimento e do método científico à análise da prática e à construção de regras que regulem a intervenção do professor". O ensino passa a ser visto como uma atividade que pode ter uma dimensão "científica" que se apoia em um conhecimento produzido pela investigação. Nesse sentido, ensinar "consiste na aplicação do método científico tanto à investigação quanto à elaboração de técnicas e intervenções, as quais, por sua vez, objetivam mudanças comportamentais úteis e adequadas, de acordo com algum centro decisório" (MIZUKAMI, 1986, p. 30). Grande parte das produções decorrentes das teorias comportamentalistas compartilharam deste entusiasmo "cientificista". 
Para Pérez Gómez (1995, p. 99), a tecnologia educativa proposta pela racionalidade técnica é portadora de diversos limites e lacunas. Em sua avaliação, os fenômenos práticos são portadores de características tais como complexidade, incerteza, instabilidade, singularidade e conflito de valores, que a tecnologia educativa não consegue objetivar na sua totalidade. "Os problemas da prática social", diz ele, "não podem ser reduzidos a problemas meramente instrumentais, em que a tarefa do profissional se resume a uma acertada escolha e aplicação de meios e de procedimentos" (1995, p. 100). As situações problemáticas da prática são muito mais complexas e singulares do que as categorias disponíveis pela tecnologia educativa. "Por essa razão", continua Pérez Gómez (1995, p. 100), "o profissional prático não pode tratar estas situações como se fossem meros problemas intrumentais, suscetíveis de resolução através da aplicação de técnicas armazenadas no seu próprio conhecimento científico-técnico". Por isso, não podemos considerar a atividade prática do professor como uma atividade exclusiva e prioritariamente técnica, mas sim uma atividade reflexiva e artística que, em certas ocasiões, pode utilizar "algumas aplicações de caráter técnico". Muitas vezes os problemas que se apresentam de forma definida são menos relevantes das práticas educativas, pois as características da incerteza, da singularidade e dos conflitos de valores que prevalecem nas zonas indeterminadas da prática não conseguem ser apreendidas pelos cânones da racionalidade técnica. Sobre isso ressalta Donald Schön, em seu livro Educando o profissional reflexivo:

\begin{abstract}
Quando uma situação problemática é incerta, a solução técnica de problemas depende da construção anterior de um problema bem-delineado, o que não é, em si, uma tarefa técnica. Quando um profissional reconhece uma situação como única não pode lidar com ela apenas aplicando técnicas derivadas de sua bagagem de conhecimento profissional. E, em situações de conflito de valores, não há fins claros que sejam consistentes em si e que possam guiar a seleção de técnica dos meios. No entanto são exatamente tais zonas indeterminadas da prática que os profissionais e os observadores críticos das profissões têm visto, com cada vez mais clareza nas últimas duas décadas, como sendo um aspecto central à prática profissional. (2000, p. 17-18)
\end{abstract}

As práticas educativas são caracterizadas por Donald Schön como "zonas indeterminadas da prática". Ministrar uma aula na "zona indeterminada da prática" implica admitir que nos defrontamos com uma problemática que é, ao mesmo tempo, incerta, singular e portadora de conflitos de valores, na qual não se pode simplesmente aplicar procedimentos técnicos que foram sistematizados no processo formativo. Cometem graves equívocos e correm sérios riscos de fracassar profissionalmente todos aqueles professores que confiam cegamente que um processo formativo será capaz de indicar todos os procedimentos técnicos para enfrentar os problemas decorrentes das práticas educativas. É nesse contexto que se apresenta a proposta de pensar o processo formativo do profissional da educação a partir da racionalidade prática que alguns teóricos denominam de "professor reflexivo". 


\section{A formação do professor reflexivo}

O que significa ser um educador reflexivo? Para que e por que ser reflexivo? Sobre o que e em que circunstâncias devemos ser reflexivos? Como podemos ser reflexivos? Para onde vamos com nossa reflexão? No que consiste compreender o profissional da educação como sendo um professor reflexivo? Essas e tantas outras questões poderiam configuram um amplo e complexo cenário que caracterizam um dos mais produtivos debates sobre a formação docente do final do século XX e início do século XXI. Isabel Alarcão (1996, p. 174), autora de diversos escritos e considerada uma das mais expressivas teóricas sobre o assunto, diz que a emergência do paradigma da reflexão nos processos formativos foi motivada pelos seguintes fatores: a necessidade do homem pensante "reencontrar a sua identidade perdida"; questionar "as finalidades da educação" e a partir disso discutir "metodologias de formação"; "gerir os seus próprios destinos e os do Mundo numa atitude de reconquista da liberdade e emancipação próprias do humano". Por todos esses fatores, o ser humano atual, "é um Homem que, de certo modo, quer reaprender a pensar".

Para Alarcão (1996, p. 175), a reflexão é "uma forma especializada de pensar", pois "implica uma prescrutação activa, voluntária, persistente e rigorosa daquilo em que se julga acreditar ou daquilo que habitualmente se pratica, evidencia os motivos que justificam as nossas acções ou convicções e ilumina as consequências a que elas conduzem". É o ato de ser reflexivo que capacita o pensamento a ser "atribuidor de sentido". As considerações de Isabel Alarcão nos remetem aos escritos do filósofo da educação americano John Dewey que, em seu livro Como pensamos, faz uma nítida distinção entre a reflexão e o ato rotineiro de pensar. Para Dewey (1959, p. 14), enquanto o pensar rotineiro é guiado por impulso, hábito, tradição ou submissão à autoridade, "a reflexão não é simplesmente uma sequência, mas uma consequência - uma ordem de tal modo consecutiva que cada ideia engendra a seguinte como seu efeito natural e, ao mesmo tempo apoia-se na antecessora ou a este se refere". Por isso, no dizer de Alarcão (1996, p. 175), "a reflexão baseia-se na vontade, no pensamento, na atitude de questionamento e curiosidade, na busca da verdade e da justiça". Sendo simultaneamente um processo lógico e psicológico, é a reflexão que "combina a racionalidade da lógica investigativa com a irracionalidade inerente à intuição e à paixão do sujeito pensante".

O conceito de professor reflexivo surgiu originariamente nos Estados Unidos como reação à concepção tecnicista de professor, a qual reduzia este a um mero aplicador de técnicas e cujo processo formativo se restringia a um treinamento de competências técnicas que poderiam instrumentalmente ser aplicadas na sua prática profissional docente. "A noção de professor reflexivo", esclarece Isabel Alarcão (2007, p. 41), "baseia-se na consciência da capacidade de pensamento e reflexão que caracteriza o ser humano como criativo e não como mero reprodutor de ideias e práticas que lhe são exteriores”. Fica explícito a noção de compreender o professor como um profissional que, ao lidar com situações de incerteza e imprevisibilidade, é capaz de ser flexível e inteligente para resolver as situações 
problemáticas que enfrenta no cotidiano de sua prática docente. $\mathrm{Na}$ análise de Donald Schön (2000, p. 17), trata-se de um profissional cuja atuação, ao mesmo tempo que mistura ciência, técnica e arte, possui uma profunda sensibilidade artística para compreender as zonas indeterminadas da práticas marcadas pela incerteza, pela singularidade e pelos conflitos de valores como já mencionamos.

Na terceira parte do seu livro Educando o profissional reflexivo, ao tratar de exemplos e experimentos de como funciona o ensino prático-reflexivo, o próprio Schön ilustra como é possível perceber formas experimentais e tradicionais de educação na perspectiva da prática reflexiva. Um dos exemplos descritos por ele é o da interação ocorrida entre o mestre violoncelista Pablo Casales e seu aluno Bernard Greenhouse. Depois de ter ensinado a tocar uma peça de Bach no violoncelo de forma impecável, a tal ponto que o aprendiz se tornou uma cópia perfeita do mestre, Casales tocou novamente de uma maneira totalmente nova. Após a execução olhou para o aprendiz e disse-lhe: "Agora você aprendeu como improvisar em Bach. De agora em diante, você estuda Bach assim" (SCHÖN, 2000, p. 139). O exemplo apresentado por Schön ilustra, ao mesmo tempo, os limites do "ato de ensinar" em relação ao "ato de aprender", assim como destaca "o poder da criatividade" que brota da nossa capacidade de agir e de intervir nos processos educativos e na vida social. O que há de semelhança neste exemplo trazido por Schön e o desafio da formação do professor reflexivo? De que maneira é possível pensar um processo produtivo de formação continuada que tenha como pressuposto um modelo reflexivo de formação de professores? Em que sentido o processo formativo do professor reflexivo se diferencia de outros modelos de formação docente?

"Na vida profissional", afirma Pérez Gómez (1995, p. 110) em seu escrito já referido no presente texto, "o professor defronta-se com múltiplas situações para as quais não encontra respostas pré-elaboradas e que não são suscetíveis de ser analisadas pelo processo clássico de investigação científica”. A suposta "realidade objetiva", tão fortemente endeusada pelos modelos técnicos e cientificistas de formação docente, não é possível de ser conhecida nas práticas escolares, pois "as realidades criam-se e constroem-se no intercâmbio psicossocial da sala de aula". Assim, as percepções do contexto social, a maneira como cada professor compreende o seu processo formativo e sua prática docente, "são um fator decisivo na orientação desse processo de produção de significados". Por isso que nas situações decorrentes da prática não existe um conhecimento profissional para cada caso-problema, o qual teria uma única solução correta, mas sim um contexto problemático no qual "o profissional competente actua refletindo na acção, criando nova realidade, experimentando, corrigindo e inventando através do diálogo que estabelece com essa mesma realidade" (PÉREZ GÓMEZ, 1995, p. 110). A prática, portanto, neste modelo de formação de professores reflexivos, adquire o papel central de todo o currículo, pois se torna, ao mesmo tempo, o lugar da aprendizagem e o espaço de construção do pensamento prático do professor. É neste cenário que a própria docência se torna objeto de investigação e a perturbadora dicotomia entre teoria e prática, que frequentemente perpassa os discursos educacionais, poderá ser superada, pois pensar a formação dos 
educadores a partir do paradigma do professor reflexivo implica assumir o desafio de refletir na e sobre a ação. Enfrentar tal desafio certamente não será tarefa fácil, pois requer novas posturas para enfrentar os próprios processos formativos e novas compreensões da própria identidade do educador.

\section{Considerações finais}

A formação docente continuada continua sendo e certamente será um dos mais importantes e centrais problemas que necessitam ser enfrentados se almejamos uma qualidade educativa. Defendemos no presente artigo que é necessário e urgente, em qualquer área de atuação, refletir sobre novas formas de exercer os saberes necessários para a prática profissional. Para isso procuramos analisar a formação continuada de professores a partir do paradigma do professor reflexivo, indicando de que forma tal paradigma pode se mostrar promissor para pensar os desafios da formação docente continuada.

Temos consciência de que o paradigma do professor reflexivo não constitui uma proposta infalível para enfrentar os desafios da formação continuada. Há mais de uma década diversos autores têm se empenhado em realizar uma crítica ao conceito de professor reflexivo. A título de exemplo podemos destacar a coletênea Professor reflexivo no Brasil: gênese e crítica de um conceito, organizado por Selma Garrido Pimenta e Evandro Ghedin (2005). Os diversos capítulos que compõe a coletânea, com autores como José Carlos Libâneo (2005), Bernard Charlot (2005), José Gimeno Sacristán (2005), Silas Borges Monteiro (2005), Evandro Ghedin (2005), Selma Garrido Pimenta (2005), dentre outros, analisam as origens, os pressupostos, os fundamentos e as características dos conceitos de professor reflexivo e professor pesquisador no movimento de valorização da profissionalização de professores, com a finalidade de pôr em discussão a ligação entre o conceito e as políticas de formação desses profissionais. A leitura cuidadosa dos diversos capítulos põe em evidência uma certa crítica à expansão generalizada de pesquisas no campo da formação de professores e indaga até que ponto são úteis aos professores e professoras que estão no dia a dia na escola.

A crítica ao paradigma do professor reflexivo realizada por esses autores mostra de certa forma os limites desse paradigma, mas ao mesmo tempo evidencia a fecundidade que tal iniciativa representa para avançar nas investigações sobre a prática docente, principalmente no que se refere à incorporação das experiências cotidianas dos professores como objeto das pesquisas educacionais. 


\section{Referências}

ALARCÃO, I. Ser professor reflexivo. In: ALARCÃO, I. (Org.). Formação reflexiva de professores: estratégias de supervisão. Porto: Porto Editora, 1996, p. 171-189.

Professores reflexivos em uma escola reflexiva. São Paulo: Cortez, 2007.

CHARLOT, B. Formação de professores: pesquisa e a política educacional. In: PIMENTA, S. G.; GHEDIN, E. (Orgs.). Professor reflexivo no Brasil: gênese e crítica de um conceito. 3. ed. São Paulo: Cortez, 2005, p. 89-108.

DEWEY, J. Como pensamos. 3. ed. Trad. Hayée Camargo Campos. São Paulo: Companhia Editora Nacional, 1959.

GIMENO SACRISTÁN, J. Tendências investigativas na formação de professores. In: PIMENTA, S. G.; GHEDIN, E. (Orgs.). Professor reflexivo no Brasil: gênese e crítica de um conceito. 3. ed. São Paulo: Cortez, 2005, p. 81-87.

GHEDIN, E. Professor reflexivo: da alienação da técnica à autonomia da crítica. In: PIMENTA, S. G.; GHEDIN, E. (Orgs.). Professor reflexivo no Brasil: gênese e crítica de um conceito. 3. ed. São Paulo: Cortez, 2005, p. 129-150.

HABERMAS, J. Conhecimento e interesse. Rio de Janeiro: Zahar, 1982.

LIBÂNEO, J. C. Adeus professor, adeus professora?: novas exigências educacionais e profissão docente. São Paulo: Cortez, 2004.

Reflexividade e formação de professores: outras oscilações do pensamento pedagógico brasileiro. In: PIMENTA, S. G.; GHEDIN, E. (Orgs.). Professor reflexivo no Brasil: gênese e crítica de um conceito. 3. ed. São Paulo: Cortez, 2005, p. 53-80.

MISUKAMI, M. da G. N. Ensino: as abordagens do processo. São Paulo: EPU, 1986.

MONTEIRO, S. B. Epistemologia da prática: o professor reflexivo e a pesquisa colaborativa. In: PIMENTA, S. G.; GHEDIN, E. (Orgs.). Professor reflexivo no Brasil: gênese e crítica de um conceito. 3. ed. São Paulo: Cortez, 2005, p. 111-128.

PÉREZ GÓMEZ, A. O pensamento prático do professor: a formação do professor como profissional reflexivo. In: NÓVOA, A. (Org.). Os professores e sua formação. Lisboa: Publicações Dom Quixote, 1995, p. 93-114.

PIMENTA, S. G. Professor reflexivo: construindo uma crítica. In: PIMENTA, S. G.; GHEDIN, E. (Orgs.). Professor reflexivo no Brasil: gênese e crítica de um conceito. 3. ed. São Paulo: Cortez, 2005, p. 17-52.

SCHÖN, D. Educando o profissional reflexivo: um novo design para o ensino e a aprendizagem. Porto Alegre: Artmed, 2000. 
A formação de professores reflexivos: a docência como objeto de investigação

* Altair Alberto Fávero - Professor Doutor da Univeridade de Passo Fundo. Passo Fundo Rio Grande do Sul, Brasil.

** Carina Tonieto -Professora de Filosofia e Sociologia na rede privada e pública de ensino. Passo Fundo Rio Grande do Sul, Brasil.

*** Marisa Fátima Roman - Doutorado em Ciências Sociais e Políticas pela Universidad Autónoma del Estado de Mexico.

\section{Correspondência}

Altair Alberto Fávero - Universidade de Passo Fundo, Instituto de Filosofia e Ciências Humanas. Campus I, São José.

CEP: 99001970 - Passo Fundo, Rio Grande do Sul - Brasil - Caixa postal: 611

E-mail:favero@upf.br

Recebido em 25 de maio de 2012

Aprovado em 07 de março de 2013 